\title{
ArtinM offers new perspectives in the development of antifungal therapy
}

\section{Luciana P. Ruas, Fernanda C. Carvalho and Maria-Cristina Roque-Barreira*}

Departamento de Biologia Celular e Molecular e Bioagentes Patogênicos, Faculdade de Medicina de Ribeirão Preto, Universidade de São Paulo, Ribeirão Preto, Brazil

\section{Edited by:}

Carlos Pelleschi Taborda, University of São Paulo, Brazil

\section{Reviewed by:}

Alfredo Goes, Universidade Federal de Minas Gerais, Brazil

Vera Lucia Garcia Calich, University of Sao Paulo, Brazil

\section{*Correspondence:}

Maria-Cristina Roque-Barreira, Departamento de Biologia Celular e Molecular e Bioagentes Patogênicos, Faculdade de Medicina de Ribeirão Preto, Universidade de São Paulo, Av. Bandeirantes, 3900, Prédio Central, 14049-900 Ribeirão Preto, São Paulo, Brazil. e-mail: mcrbarre@fmrp.usp.br
The thermally dimorphic fungus Paracoccidioides brasiliensis is the causative agent of paracoccidioidomycosis (PCM), the most frequent systemic mycosis that affects the rural populations in Latin America. Despite significant developments in antifungal chemotherapy, its efficacy remains limited since drug therapy is prolonged and associated with toxic side effects and relapses. In response to these challenges, it is now recognized that several aspects of antifungal immunity can be modulated to better deal with fungal infections. A common idea for halting fungal infections has been the need to activate a cellbased, pro-inflammatory Th1 immune response to improve the fungal elimination. ArtinM, a D-mannose binding lectin from Artocarpus heterophyllus, has the property of modulating immunity against several intracellular pathogens. Here, we review the immunomodulatory activity of ArtinM during experimental PCM in mice. Both prophylactic and therapeutic protocols of ArtinM administration promotes a Th1 immune response balanced by IL-10, which outstandingly reduces the fungal load in organs of the treated mice while maintaining a controlled inflammation at the site of infection. A carbohydrate recognition-based interaction of ArtinM with Toll-like receptor 2 (TLR2) accounts for initiating the immunomodulatory effect of the lectin. The precise identification of the TLR2 N-glycan(s) targeted by ArtinM may support novel basis for the development of antifungal therapy.

Keywords: Paracoccidioides brasiliensis, ArtinM, immunomodulation

\section{BALANCING RESISTANCE AND TOLERANCE TO FUNGI}

The two main components of the host immune response to fungi, namely, resistance (the ability to limit fungal burden) and tolerance (the ability to limit host damage caused by immune response or other mechanisms) highlight the bipolar nature of the inflammatory process in fungal infections. Both components must be considered when developing any therapeutic or prophylactic antifungal procedure.

Dendritic cells (DCs) are primarily responsible for antigen recognition, decoding this information, and then stimulating various $\mathrm{T}$ cell pathways using specific cytokine signals. The $\mathrm{T}$ cell subsets in turn secrete cytokines that mediate protective or detrimental/pathogenic effects on phagocytes and the inflammatory process. The primary protective response against fungal disease is the cell-mediated Th1 response (Calich and Kashino, 1998; Netea et al., 2004; Zhang et al., 2009; Ito, 2011). Th1 lymphocytes produce IFN- $\gamma$, which stimulates the antifungal activity of PMN and macrophages.

Otherwise, some cytokines such as IL-4 and IL-13 provide signals that favor a Th2-mediated immune response by lymphocytes. By diminishing the Th1 cell response and promoting antibody production and $\mathrm{T}$ regulatory cells, it favors fungal infections, fungus-associated allergic responses, and disease relapse (Benard et al., 1997; Netea et al., 2004; Müller et al., 2007). Therefore, Th2 immunity is associated with severe and disseminated forms of fungal infections. This pattern is well established and reported in cryptococcosis (Müller et al., 2007), paracoccidioidomycosis
(PCM; Calich and Kashino, 1998; Ruas et al., 2009), and candidiasis (Netea et al., 2004; Haraguchi et al., 2010).

In this review, we discuss the role of a plant lectin named ArtinM in a murine model of Paracoccidioides brasiliensis infection, highlighting its immunomodulatory properties and the importance of the modulation of a cell-mediated immune response in the resistance to the fungus. We discuss the aspects that make this lectin an excellent candidate for further studies as a potential therapeutic for severe cases of PCM in human patients or for development as a prophylactic for individuals at risk for severe disease.

\section{IMMUNITY TO PARACOCCIDIOIDES BRASILIENSIS INFECTION}

The most common human systemic mycosis in Latin America is PCM, which is caused by the dimorphic fungus P. brasiliensis. Infection occurs by inhalation of fungal spores or particles, which transform into the pathogenic yeast form after reaching the pulmonary alveolar epithelium (Restrepo-Moreno, 1993). Yeast can either be eliminated by immune-competent cells or disseminate to other tissues through lymphatic and hematogenous routes, resulting in a wide spectrum of clinical manifestations, which vary from asymptomatic, benign and localized to severe and disseminated forms (Borges-Walmsley et al., 2002). Clinical and experimental evidences indicate that, similar to other systemic mycosis, Th1 immunity exerts a singular role in the asymptomatic form of PCM, while a Th2 pattern is associated with progression to 
the severe disease form (Cano etal., 1998; Karhawi et al., 2000; Benard etal., 2001; Oliveira etal., 2002; Peraçoli etal., 2003; Ruas et al., 2009).

These immune patterns of resistance or susceptibility to fungal infections have been studied in murine models of infection that simulate human mycosis. Animal models facilitate the study of immune response mechanisms involved in PCM. Resistant mice produce early and sustained levels of IFN- $\gamma$ and IL-2, whereas susceptible mice produce low levels of IFN- $\gamma$, but significant levels of IL-5 and IL-10 (Calich and Kashino, 1998; Kashino et al., 2000). Murine models have also showed that IFN- $\gamma$ and TNF- $\alpha$ activate macrophages to exert effects against $P$. brasiliensis (Brummer et al., 1989; Gonzales et al., 2003). The essential role of these cytokines has been further demonstrated using mice that are genetically deficient in either the IFN- $\gamma$ or the TNF- $\alpha$ receptor (Cano et al., 1998; Souto et al., 2000). Indeed, the presence of cytokines accounting for the activation of macrophages, which is necessary for fungal killing, has been consistently documented (Gonzales et al., 2000; Moreira et al., 2008, 2010).

The importance of innate immunity in the recognition of fungi has been extensively reviewed elsewhere (Roeder etal., 2004; Romani, 2004), and it has been recently characterized for P. brasiliensis infection (Loures et al., 2009, 2010, 2011). The lack of the receptors Toll-like receptor 2 (TLR2) or TLR4 did not alter the survival rates of mice infected with $P$. brasiliensis. TLR2 knockout $(\mathrm{KO})$ mice infected with $P$. brasiliensis presented with increased Th17 immunity, associated with an impaired regulatory $\mathrm{T}$ cell expansion, which resulted in an uncontrolled inflammatory reaction. Therefore, the authors concluded that the presence of TLR2 in P. brasiliensis infection is important to downregulate Th17 immunity and lung pathological condition (Loures et al., 2009). TLR4-deficient mice presented lower fungal loads than the TLR4-normal mice, but these mice were unable to clear the infection completely owing to enhanced regulatory $\mathrm{T}$ cells and low inflammation (Loures et al., 2010).

Current treatment for PCM relies on antifungal chemotherapy to control the disease. Clinically, the antifungal drugs most commonly used for PCM treatment include amphotericin B, sulfa derivatives, and azoles, but their toxicity can be a limiting factor in the treatment (Mendes et al., 1994). Treatment regimens with these agents often require extended periods of maintenance therapy, which may range from months to years, and are usually associated with relapses (Shikanai-Yasuda et al., 2006). Moreover, even after prolonged administration of these drugs, there is no guarantee that the fungus will be completely eradicated.

Based on these data, there is a strong need for alternative clinical treatments to chemotherapy. Researchers have focused their efforts in investigating fungal components able to promote cellular immune responses and host protection. Immunization with heatshock proteins (HSPs) from P. brasiliensis has also been shown to provide some degree of protection against experimental disease (Soares et al., 2008; Ribeiro et al., 2009, 2010). Recently, it was shown that plasmid immunization with a peptide derived from the $43-\mathrm{kDa}$ glycoprotein antigen from the fungus, called $\mathrm{P} 10$, was shown to be protective against PCM, inducing a reduction in fungal load in the lungs of experimentally infected mice
(Rittner et al., 2012). Although these studies focused on the use of fungal components to immunize mice against $P$. brasiliensis infection, it was shown that immunotherapy with a Th1-inducing adjuvant that was independent of $\mathrm{Pb}$ antigens has a beneficial effect against PCM (Oliveira et al., 2008). A single-dose administration of the adjuvant in infected mice was sufficient to restore their ability to mount an effective immune response to the fungus. These data support that stimulation of the host Th1 immune response is a promising approach toward expanding available treatment options for systemic fungal diseases, including PCM. Moreover, Th1 stimulation may be achieved irrespective of whether P. brasiliensis antigens are used, providing new possibilities for the use of alternative drugs against the disease

\section{IMMUNOMODULATION BY ArtinM}

ArtinM (also known as $\mathrm{KM}^{+}$or Artocarpin) (Pereira Da Silva et al., 2008) is a lectin from Artocarpus heterophyllus seeds that specifically recognizes the trisaccharide Man $\alpha$ 1-3 [Man $\alpha 1-6]$ Man core of $\mathrm{N}$-glycans. ArtinM is a homotetramer formed by $13-\mathrm{kDa}$ subunits, each one corresponding to a $\beta$-barrel, with a $\beta$-prism folding, which includes a carbohydrate-recognition domain (CRD). ArtinM cDNA has been cloned and heterologously expressed in Saccharomyces cerevisiae and Escherichia coli (Silva et al., 2005). Native (ArtinM) and recombinant (rArtinM) proteins share the same sugar recognition specificity and are equivalents in terms of the kinetics of binding affinity to a glycoligand (Pesquero et al., 2010). The ArtinM CRD is preserved in $\operatorname{rArtinM}$, and the recombinant protein retains the same biological properties as the native form, with the advantage that it does not form oligomers. ArtinM possesses many relevant biological properties in cells of the immune system, which is reflected in the modulation of immunity during infection with intracellular pathogens. The lectin acts on mast cells and induces degranulation (Moreno et al., 2003). It also acts on neutrophils and induces haptotactic migration, as well as phenotypic and functional changes, which include intracellular tyrosine phosphorylation, shedding of L-selectin, release of inflammatory mediators, phagocytic and cell-killing activities, and increased expression of TLR2 (Ganiko et al., 2005; Toledo et al., 2009).

The pioneering observation on the ArtinM immunomodulatory activity was its ability to induce IL-12 production in murine macrophages. This cytokine production then promoted a switch in the BALB/c mouse immune response from Th2- to Th1mediated immunity against Leishmania major antigens. Cytokine production was dependent on the CRD of the lectin, since IL-12 production was selectively inhibited by D-mannose, which is an ArtinM-specific ligand (Panunto-Castelo et al., 2001).

Additional studies have shown that the benefits provided by the immunomodulation induced by ArtinM can be extended to several infections in which a Th1-biased immunity is necessary for resistance, including the murine model of Candida albicans infection. Infected mice that were treated with ArtinM developed Th1- and Th17-mediated immune responses; their macrophages and neutrophils exhibited increased phagocytical and candidacidal activities (Custodio et al., 2011). The augmented phagocytosis of yeast cells by macrophages from ArtinM-treated mice occurred via mannose and dectin-1. This effect explains 
the faster clearance of $C$. albicans in the initial phase of infection in mice, which favors ArtinM-induced protection against disseminated candidiasis (Loyola et al., 2012).

Knowledge about the immunomodulatory effects of ArtinM on PCM is derived from studies that used an experimental model developed in BALB/c mice that had been intravenously infected with $P$. brasiliensis. Trials involving several protocols for the therapeutic and prophylactic administration of ArtinM showed that the most effective therapeutic protocol consisted of a single subcutaneous injection of ArtinM 10 days after infection, whereas the best prophylaxis was attained by the administration of two subcutaneous injections of ArtinM on day 10 and day 3 before infection. The beneficial effects of therapeutic and prophylactic regimens (Coltri et al., 2008, 2010) of ArtinM on the severity of P. brasiliensis infection, which manifested on day 30 post-infection, included marked decrease in fungal burden and absence of granulomas in the lungs, which exhibited a well-preserved bronchoalveolar architecture. This pattern was in contrast to what was observed in the untreated mice, which had disseminated infection and multiple sites of focal and confluent epithelioid granulomas with lymphomonocytic halos circumscribing a high number of viable and non-viable yeast cells (Figure 1). The lesions were larger and still disseminated on day 60 after infection, while ArtinMtreated mice had no granulomas or yeast cells in the liver, spleen or lung tissue.

The advantages of ArtinM administration correlate with an adequate milieu of pulmonary mediators. Lung homogenates from mice that were infected with $P$. brasiliensis and then subjected to prophylactic or therapeutic ArtinM regimen showed higher levels of the pro-inflammatory cytokines IL-12 and TNF$\alpha$, and NO. ArtinM administration drove cytokine production from a Th2 immune response pattern to a Th1 immune response pattern. High concentrations of IL-4 and low concentrations of IFN- $\gamma$ were detected in untreated control mice, whereas in ArtinM-treated mice, lower IL- 4 and higher IFN- $\gamma$ concentrations were stably produced during the course of the disease, as illustrated in Figure 2. It was clear that a drive toward Th1mediated immunity is stimulated in vivo by ArtinM. Interestingly,
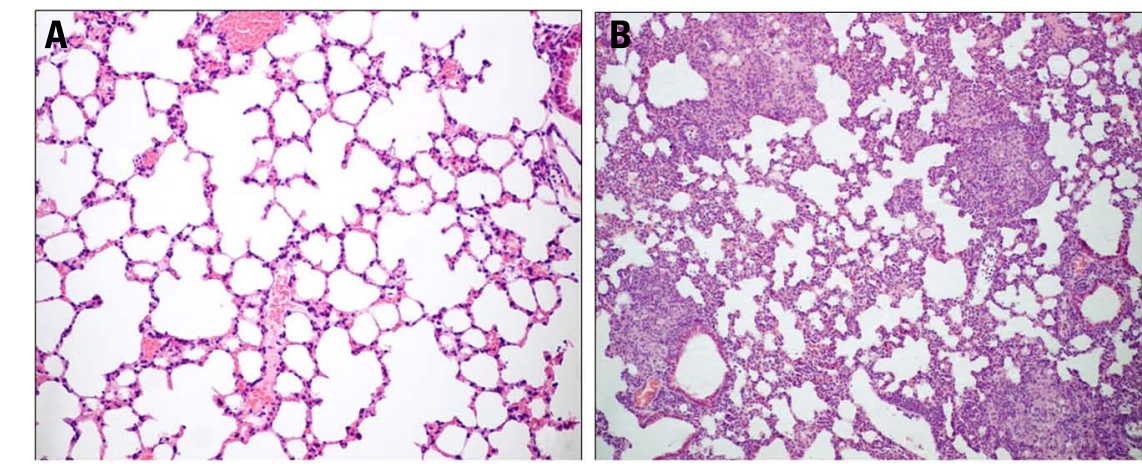

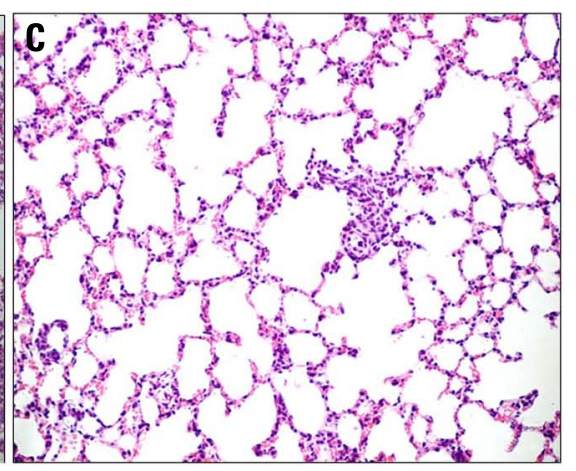

FIGURE 1 | ArtinM administration prevents pulmonary lesions in P. brasiliensis-infected mice. Lung histopathology of uninfected mice (A), $P$. brasiliensis-infected mice (B), and P. brasiliensis-infected mice treated with ArtinM (C). P. brasiliensis-infected mice display extensive and confluent lesions in the lungs, with epithelioid granulomas surrounding a large number of yeast cells. Infected mice treated with ArtinM present no granulomas, and lung architecture is similar to that of uninfected mice. The lung sections were stained with H\&E (Modified from Coltri et al., 2010).

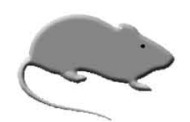

\section{P. brasiliensis-infected mice}

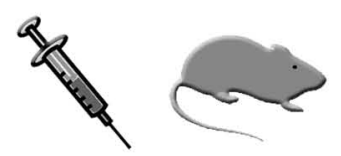

\section{P. brasiliensis-infected mice treated with ArtinM}

FIGURE 2 | Treatment with ArtinM induces Th1 immunity. Mice were infected with $P$. brasiliensis yeast cells, and then treated or not with ArtinM. On day 30 after infection, the mouse lung tissue was analyzed for
IL-4, IFN- $\gamma$ and NO concentrations. ArtinM treatment was associated with lower IL-4 and higher IFN- $\gamma$ and NO pulmonary levels, which reflected in lower fungal load. 
stable IL-10 production was also verified in the ArtinM-treated mice, indicating that the induced Th1 response is balanced by the effects of this anti-inflammatory cytokine. Studies involving IL-12 KO mice have demonstrated the importance of IL-12 for ArtinM-mediated beneficial effects on experimental PCM. When these mice were infected with $P$. brasiliensis, treatment with ArtinM exerted no protective effects against the infection. The parallel utilization of an ArtinM recombinant form to treat the $P$. brasiliensis-infected mice has provided evidence that the administration of ArtinM or its recombinant form (rArtinM) exerts an equally protective effect against $P$. brasiliensis infection (Coltri et al., 2008, 2010).

\section{ArtinM TARGETS TLR2 N-GLYCANS TO INDUCE IL-12 PRODUCTION}

The role of the 70-kDa heterodimeric cytokine IL-12 in the activation of type 1 immune response is largely recognized. Its bioactive IL-12p70 form is composed of two disulfide-linked subunits: a $40-\mathrm{kDa}$ heavy chain of (p40) and a 35-kDa light chain (p35). Macrophages and DCs are the major cell types producing this cytokine, which is released as the biologically inactive peptide IL-12p40 as well as the biologically active IL-12p70. IL-12 acts on $\mathrm{T}$ lymphocytes and natural killer (NK) cells, and induces IFN- $\gamma$ production. This hallmark Th1 cytokine is responsible for $\mathrm{T}$ cell proliferation and enhancement of macrophage cytotoxic activity (Kobayashi et al., 1989; Wolf et al., 1991).

IL-12 production by phagocytes is generally initiated by the interaction of cell-surface TLRs with pathogen-associated molecular patterns (PAMPs). TLRs constitute a protein family of cellular receptors that mediate recognition of microbial pathogens and subsequent inflammatory response in vertebrates. These receptors confer PAMP recognition and their signaling triggers synthesis followed by release of pro-inflammatory cytokines, and induces expression of co-stimulatory molecules for promoting activation of adaptive immunity during antigen presentation (Janeway and Medzhitov, 2002). Upon recognition of respective PAMPs, TLRs recruit a specific set of adaptor molecules that harbor TIR domains, such as MyD88 and TRIF, and initiate downstream signaling events that lead to the activation of the transcription factor and its translocation into the nucleus to induce the expression of pro-inflammatory genes, including the IL-12-coding gene. Inflammatory cytokines are released from the cell into the extracellular matrix, and they promote the recruitment of neutrophils to the site of infection, activation of macrophages, and induction of IFN- $\gamma$ stimulated genes, resulting in direct killing of invading pathogens. Moreover, activation of TLR signaling leads to the maturation of DCs, which contributes to the induction of adaptive immunity (West et al., 2006).

The involvement of MyD88-mediated signaling in the enhanced secretion of ArtinM-induced IL-12 was proved by the fact that macrophages from MyD88KO mice did not respond to in vitro stimulation with the lectin. To investigate whether TLR2 was involved in ArtinM-induced IL-12 production, an in vitro assay was performed to quantify the IL-12 concentrations released by ArtinM-stimulated macrophages from the TLR2KO or TLR4-deficient mice. Macrophages from TLR2KO mice, distinctly from those from TLR4-deficient or WT mice, were unable to produce IL-12 in response to ArtinM stimulus. Moreover, IL-12 production by ArtinM-stimulated macrophages was inhibited by D-mannose, which indicates that its production is dependent on the lectin CRD. These results demonstrate that TLR2 plays a critical role in ArtinM-mediated production of IL-12 (Coltri et al., 2008).

Potential $N$-linked glycosylation sites have been revealed by amino acid sequencing analysis of all known TLRs. Several lines of evidence indicate that oligosaccharides attached to TLRs play important roles in the recognition of PAMPs, and in the formation of a functional receptor complex on the cell surface (Ohnishi et al., 2001,2003; da Silva Correia and Ulevitch, 2002; Weber et al., 2004). Concerning human TLR2, its ectodomain contains $N$-glycans linked to the residues Asn114, Asn199, Asn414, and Asn442; among them, the glycan linked to Asn442 was reported to contribute to efficient secretion of the TLR2 ectodomain (Weber et al., 2004) and cellular recognition of PAMPS (Kataoka et al., 2006). Direct interaction of ArtinM with TLR2 was further demonstrated by a gene reporter assay involving TLR2-transfected cells (unpublished data). Currently, TLR2 mutants for the ectodomain glycosylation sites (generated in Dr. Nicholas Gay's laboratory, University of Cambridge, UK) are being used to identify the glycan(s) targeted by ArtinM.

\section{CONCLUDING REMARKS AND PERSPECTIVES}

ArtinM administration interferes with the outcome of $P$. brasiliensis infection by modulating host immunity according to the following events:

(a) recognition of TLR2 glycans by the lectin,

(b) induction of IL-12 production,

(c) generation of Th1-balanced immunity, and

(d) protection against $P$. brasiliensis, mainly manifested by the occurrence of milder lung lesions and low fungal burden.

IL-12-dependent mechanism of protection is a process triggered by the MyD88/TLR2 signaling pathway. Detection of IL-10 production in ArtinM-treated animals reveals that the induced Th1-prone immune response is regulated in a way that prevents systemic immune pathology, as indicated by the absence of exacerbated inflammatory lesions in ArtinM-treated animals (Coltri et al., 2008, 2010). As part of a study on the pleiotropic activities of ArtinM, we are trying to identify the IL-10-producing cells.

Observations concerning the immunomodulatory effects of ArtinM support the use of this protein, in its native or recombinant form, as an immunomodulatory agent that can stimulate balanced Th1 immunity, which is required to protect the host against fungal infection. Otherwise, complete characterization of the $N$-glycan(s) recognized by ArtinM in TLR2 molecules may provide an adequate target for the development of novel antifungal therapies.

\section{ACKNOWLEDGMENTS}

We thank Dr. Maria Aparecida de Souza for helpful discussions. Research was supported by grants of FAPESP (00/09333-2 and 06/60642-2) and CNPq (350418/00-4). 


\section{REFERENCES}

Benard, G., Mendes-Giannini, M. J., Juvenale, M., Miranda, E. T., and Duarte, A. J. S. (1997). Immunosuppression in paracoccidioidomycosis: $\mathrm{T}$ cell hyporesponsiveness to two Paracoccidioides brasiliensis glycoproteins that elicit strong humoral immune response. J. Infect. Dis. 175, 1263-1267.

Benard, G., Romano, C. C., Cacere, C. R., Juvenale, M., Mendes-Giannini, M. J., and Duarte, A. J. S. (2001). Imbalance of IL-2, IFN-gamma and IL-10 secretion in the immunosuppression associated with human paracoccidioidomycosis. Cytokine 13, 248-252.

Borges-Walmsley, M. I., Chen, D., Shu, X., and Walmsley, A. R. (2002). The pathobiology of Paracoccidioides brasiliensis. Trends Microbiol. 10, 80-87.

Brummer, E., Hanson, L. H., Restrepo, A., and Stevens, D. A. (1989). Intracellular multiplication of Paracoccidioides brasiliensis in macrophages: killing and restriction of multiplication by activated macrophages. Infect. Immun. 57, 2289-2294.

Calich, V. L. G., and Kashino, S. S. (1998). Cytokines produced by susceptible and resistant mice in the course of Paracoccidioides brasiliensis infection. Braz. J. Med. Biol. Res. 31, 615-623.

Cano, L. E., Kashino, S. S., Arruda, C., André, D., Xidieh, C. F., SingerVermes, L. M., Vaz, C. A. C., Burger, E., and Calich, V. L. G. (1998). Protective role of gamma interferon in experimental pulmonary paracoccidioidomycosis. Infect. Immun. 66, 800-806.

Coltri, K. C., Oliveira, L. L., Pinzan, C. F., Vendruscolo, P. E., Martinez, R., Goldman, M. H., Panunto-Castelo, A., and Roque-Barreira, M. C. (2008). Therapeutic administration of $\mathrm{KM}^{+}$ lectin protects mice against Paracoccidioides brasiliensis infection via interleukin-12 production in a tolllike receptor 2-dependent mechanism. Am. J. Pathol. 173, 423-432.

Coltri, K. C., Oliveira, L. L., Ruas, L. P., Vendruscolo, P. E., Goldman, M. H., Panunto-Castelo, A., and RoqueBarreira, M. C. (2010). Protection against Paracoccidioides brasiliensis infection conferred by the prophylactic administration of native and recombinant ArtinM. Med. Mycol. 48, 792-799.

Custodio, L. A., Loyola, W., ConchonCosta, I., Da Silva Quirino, G. F., and Felipe, I. (2011). Protective effect of Artin M from extract of Artocarpus integrifolia seeds by Th1 and Th17 immune response on the course of infection by Candida albicans. Int Immunopharmacol. 11, 1510-1515.

da Silva Correia, J., and Ulevitch, R. J. (2002). MD-2 and TLR4 $\mathrm{N}$-linked glycosylations are important for a functional lipopolysaccharide receptor. J. Biol. Chem. 277, 1845-1854.

Ganiko, L., Martins, A. R., Freymuller, E., Mortara, R. A., and Roque-Barreira, M. C. (2005). Lectin $\mathrm{KM}^{+}$-induced neutrophil haptotaxis involves binding to laminin. Biochim. Biophys. Acta 1721, 152-163.

Gonzales, A., Gregori, W., Velez, D., Restrepo, A., and Cano, L. E. (2000). Nitric oxide participation in the fungicidal mechanism of gamma interferon-activated murine macrophages against Paracoccidioides brasiliensis conidia. Infect. Immun. 68, 2546-2552.

Gonzales, A., Sahaza, J. H., Ortiz, B. L., Restrepo, A., and Cano, L. E. (2003). Production of proinflammatory cytokines during the early stages of experimental Paracoccidioides brasiliensis infection. Med. Mycol. 41, 391-399.

Haraguchi, N., Ishii, Y., Morishima, Y., Yoh, K., Matsuno, Y., Kikuchi, N., Sakamoto, T., Takahashi, S., and Hisawa, N. (2010). Impairment of host defense against disseminated candidiasis in mice overexpressing GATA-3. Infect. Immun. 78, 23022311.

Ito, J. I. (2011). T cell immunity and vaccines against invasive fungal diseases. Immunol. Invest. 40, 825-838.

Janeway, C. A., and Medzhitov, R. (2002). Innate immune recognition. Annu. Rev. Immunol. 20, 197-216.

Karhawi, A. S., Colombo, A. L., and Salomão, R. (2000). Production of IFN-gamma is impaired in patients with paracoccidioidomycosis during active disease and is restored after clinical remission. Med. Mycol. 38, 225-229.

Kashino, S. S., Fazioli, R. A., CafalliFavati, C., Meloni-Bruneri, L. H., Vaz, C. A. C., Burger, E., Singer, L. M., and Calich, V. L. G. (2000). Resistance to Paracoccidioides brasiliensis infection is linked to a preferential Th1 immune response, whereas susceptibility is associated with absence of IFN-gamma production. J. Interferon Cytokine Res. 20, 89-97.

Kataoka, H., Yasuda, M., Iyori, M., Kiura, K., Narita, M., Nakata, T., and Shibata, K. I. (2006). Roles of $N$ linked glycans in the recognition of microbial lipopeptides and lipoproteins by TLR2. Cell. Microbiol. 8, 1199-1209.
Kobayashi, M., Fitz, L., Ryan, M., Hewick, R. M., Clark, S. C., Chan S., Loudon, R., Shennan, F., Perussia, B., and Trinchieri, G. (1989). Identification and purification of natural killer cell stimulatory factor (NKSF), a cytokine with multiple biologic effects on human lymphocytes. $J$. Exp. Med. 170, 827-846.

Loures, F. V., Pina, A., Felonato, M., Araujo, E. F., Leite, K. R., and Calich, V. L. G. (2010). Toll-like receptor 4 signaling leads to severe fungal infection associated with enhanced proinflammatory immunity and impaired expansion of regulatory $\mathrm{T}$ cells. Infect. Immun. 78, 1078-1088.

Loures, F. V., Pina, A., Felonato, M., and Calich, V. L. G. (2009). TLR2 is a negative regulator of Th17 cells and tissue pathology in a pulmonary model of fungal infection. J. Immunol. 183, 1279-1290.

Loures, F. V., Pina, A., Felonato, M., Feriotti, C., Araujo, E. F., and Calich, V. L. G. (2011). MyD88 signaling is required for efficient innate and adaptive immune responses to Paracoccidioides brasiliensis infection. Infect. Immun. 79, 2470-2480.

Loyola, A. M., Custodio, L. A., Felipe, I., Conchon-Costa, I., Carvalho, P. G., Quirino, G. F., Silva, L. F., and Gaziri, L. C. (2012). Artin M enhances TNF- $\alpha$ production and phagocytosis of Candida albicans mediated by dectin-1 and mannose receptors. Int. Immunopharmacol. 12, 378-383.

Mendes, R. P., Negroni, R., and Arechavala, A. (1994). "Treatment and control of cure," in Paracoccidioidomycosis, eds M. Franco, C. S. Lacaz, A. Restrepo, and G. Del Negro (Boca Raton: CRC Press), 373-392.

Moreira, A. P., Dias-Melício, L. A., Peraçoli, M. T. S., Calvi, S. A., and Victoriano de Campos Soares, A. M. (2008). Killing of Paracoccidioides brasiliensis yeast cells by IFN-gamma and TNF-alpha activated murine peritoneal macrophages: evidence of $\mathrm{H}_{2} \mathrm{O}_{2}$ and $\mathrm{NO}$ effector mechanisms. Mycopathologia 166, 17-23.

Moreira, A. P., Dias-Melício, L. A., and Soares, A. M. V. C. (2010). Interleukin-10 but not Transforming Growth Factor beta inhibits murine activated macrophages Paracoccidioides brasiliensis killing: effect on $\mathrm{H}_{2} \mathrm{O}_{2}$ and $\mathrm{NO}$ production. Cell. Immunol. 263, 196-203.

Moreno, A. N., Jamur, M. C., Oliver, C., and Roque-Barreira, M. C. (2003). Mast cell degranulation induced by lectins: effect on neutrophil recruitment. Int. Arch. Allergy Immunol. 132, 221-230.
Müller, U., Stenzel, W., Köhler, G., Werner, C., Polte, T., Hansen, G., Schütze, N., Straubinger, R. K., Blessing, M., Mckenzie, A. N., Brombacher, F., and Alber, G. (2007). IL 13 induces disease-promoting type 2 cytokines, alternatively activated macrophages and allergic inflammation during pulmonary infection of mice with Cryptococcus neoformans. J. Immunol. 179, 5367-5377.

Netea, M. G., Sutmuller, R., Hermann, C., Van Der Graaf, C. A., Van Der Meer, J. W., Van Krieken, J. H., Hartung, T., Adema, G., and Kullberg, B. J. (2004). Toll-like receptor 2 suppresses immunity against Candida albicans through induction of IL-10 and regulatory $\mathrm{T}$ cells. J. Immunol. 172, 3712-3718.

Ohnishi, T., Muroi, M., and Tanamoto, K. (2001). N-linked glycosylations at $\operatorname{Asn}(26)$ and $\operatorname{Asn}(114)$ of human MD-2 are required for toll-like receptor 4-mediated activation of NFkappaB by lipopolysaccharide. J. Immunol. 167, 3354-3359.

Ohnishi, T., Muroi, M., and Tanamoto, K. (2003). MD-2 is necessary for the toll-like receptor 4 protein to undergo glycosylation essential for its translocation to the cell surface. Clin. Diagn. Lab. Immunol. 10, 405-410.

Oliveira, L. L., Coltri, K. C., Cardoso, C. R., Roque-Barreira, M. C., and Panunto-Castelo, A. (2008). T helper 1-inducing adjuvant protects against experimental Paracoccidioidomycosis. PLoS Negl. Trop. Dis. 2, e183. doi: 10.1371/journal.pntd.0000183

Oliveira, S. J., Mamoni, R. L., Musatti, C. C., Papaiordanou, P. M. O., and Blotta, M. H. S. L. (2002). Cytokines and lymphocyte proliferation in juvenile and adult forms of paracoccidioidomycosis: comparison with infected and non-infected controls. Microbes Infect. 4, 139-144.

Panunto-Castelo, A., Souza, M. A., Roque-Barreira, M. C., and Silva, J. S. (2001). KM(+), a lectin from Artocarpus integrifolia, induces IL-12 $\mathrm{p} 40$ production by macrophages and switches from type 2 to type 1 cellmediated immunity against Leishmania major antigens, resulting in $\mathrm{BALB} / \mathrm{c}$ mice resistance to infection. Glycobiology 11, 1035-1042.

Peraçoli, M. T. S., Kurokawa, C. S., Calvi, S. A., Mendes, R. P., Pereira, P. C. M., Marques, S. A., and Soares, A. M. V. C. (2003). Production of proand anti-inflammatory cytokines by monocytes from patients with paracoccidioidomycosis. Microbes Infect. 5, 413-418.

Pereira Da Silva, G., Roque-Barreira, M. C., and Van Damme, E. J. M. 
(2008). Artin M: a rational substitution for the names artocarpin and $\mathrm{KM}^{+}$. Immunol. Lett. 119, 114-115.

Pesquero, N. C., Pedroso, M. M., Watanabe, A. M., Goldman, M. H., Faria, R. C., Roque-Barreira, M. C., and Bueno, P. R. (2010). Real-time monitoring and kinetic parameter estimation of the affinity interaction of jArtinM and rArtinM with peroxidase glycoprotein by the electrogravimetric technique. Biosens. Bioeletron. 26, 36-42.

Restrepo-Moreno, A. (1993). "Paracoccidioidomycosis," in Infections, Agents and Pathogenesis - Fungal Infections and Immune Responses, eds J. W. Murphy, H. Friedman, and M. Bendinelli (Berlin: Springer), 251-276.

Ribeiro, A. M., Bocca, A. L., Amaral, A. C., Faccioli, L. H., Galetti, F. C., Zarate-Blades, C. R., Figueiredo, F., Silva, C. L., and Felipe, M. S. S. (2009). DNAhsp65 vaccination induces protection in mice against Paracoccidioides brasiliensis infection. Vaccine 27, 606-613.

Ribeiro, A. M., Bocca, A. L., Amaral, A. C., Souza, A. C., Faccioli, L. H., Coelho-Castelo, A. A., Figueiredo, F., Silva, C. L., and Felipe, M. S. S. (2010). HSP65 DNA as therapeutic strategy to treat experimental paracoccidioidomycosis. Vaccine 28, 1528-1534.

Rittner, G. M., Muñoz, J. E., Marques, A. F., Nosanchuk, J. D., Taborda, C. P., and Travassos, L.
R. (2012). Therapeutic DNA vaccine encoding peptide P10 against experimental paracoccidioidomycosis. PLoS Negl. Trop. Dis. 6, e1519. doi:10.1371/journal.pntd.0001519

Roeder, A., Kirschning, C. J., Rupec, R. A., Schaller, M., Weindl, G., and Korting, H. C. (2004). Toll-like receptors as key mediators in innate antifungal immunity. Med. Mycol. 42, 485-498.

Romani, L. (2004). Immunity to fungal infections. Nat. Rev. Immunol. 4, $1-13$.

Ruas, L. P., Bernardes, E. S., Fermino, M. L., De Oliveira, L. L., Hsu, D. K., Liu, F. T., Chammas, R., and Roque-Barreira, M. C. (2009). Lack of galectin-3 drives response to Paracoccidioides brasiliensis toward a Th2-biased immunity. PLoS ONE 4, e4519. doi: 10.1371/journal.pone. 0004519

Shikanai-Yasuda, M. A., Telles-Filho, Q., Mendes, R. P., Colombo, A. L., and Moretti, M. L. (2006). Guidelines in paracoccidioidomycosis. Rev. Soc. Bras. Med. Trop. 39, 297-310.

Silva, L. L., De Molfetta-Machado, J. B., Panunto-Castelo, A., Denecke, J., Goldman, G. H., Roque-Barreira, M. C. G., and Goldman, M. H. (2005). cDNA cloning and functional expression of $\mathrm{KM}^{+}$, the mannosebinding lectin from Artocarpus integrifolia seeds. Biochim. Biophys. Acta 1726, 251-260.

Soares, C. M. A., Mendes-Giannini, M. J., Felipe, M. S. S., and Chaturvedi, V. (2008). A centennial: discovery of Paracoccidioides brasiliensis. Mycopathologia 165, 179-181.

Souto, J. T., Figueiredo, F., Furlanetto, A. B., Pfeffer, K., Rossi, M. A., and Silva, J. S. (2000). Interferon- $\gamma$ and tumor necrosis factor- $\alpha$ determine resistance to Paracoccidioides brasiliensis infection in mice. Am. J. Pathol. 156, 1811-1820.

Toledo, K. A., Scwartz, C., Oliveira, A. F., Conrado, M. C., Bernardes, E. S., Fernandes, L. C., Roque-Barreira, M. C., Pereira Da Silva, G., and Moreno, A. N. (2009). Neutrophil activation induced by ArtinM: release of inflammatory mediators and enhancement of effector functions. Immunol. Lett. 123, 14-20.

Weber, A. N., Morse, M. A., and Gay, N. J. (2004). Four N-linked glycosylation sites in human toll-like receptor 2 cooperate to direct efficient biosynthesis and secretion. J. Biol. Chem. 279, 34589-34594.

West, A. P., Koblansky, A. A., and Ghosh, S. (2006). Recognition and signaling by toll-like receptors. Annu. Rev. Cell Dev. Biol. 22, 409-437.

Wolf, S. F., Temple, P. A., Kobayashi, M. Young, D., Dicig, M., Lowe, L., Dzialo, R., Fitz, L., Ferenz, C., Hewick, R. M., Kelleher, K., Hernnann, S. H., Clark, S. C., Azzoni, L., Chan, S. H., Trinchieri, G., and Perussia, B. (1991). Cloning of cDNA for natural killer cell stimulatory factor, a heterodimeric cytokine with multiple biologic effects on $\mathrm{T}$ and natural killer cells. J. Immunol. 146, 3074-3081.
Zhang, Y., Wang, F., Tompkins, K. C., Mcnamara, A., Jain, A. V., Moore, B. B., Toews, G. B., Huffnagle, G. B., and Olszewski, M. A. (2009). Robust Th1 and Th17 immunity supports pulmonary clearance but cannot prevent systemic dissemination of highly virulent Cryptococcus neoformans H99. Am. J. Pathol. 175, 2489-2500.

Conflict of Interest Statement: The authors declare that the research was conducted in the absence of any commercial or financial relationships that could be construed as a potential conflict of interest.

Received: 22 March 2012; paper pending published: 05 April 2012; accepted: 29 May 2012; published online: 15 June 2012.

Citation: Ruas LP, Carvalho FC and Roque-Barreira M-C (2012) ArtinM offers new perspectives in the development of antifungal therapy. Front. Microbio. 3:218. doi: 10.3389/fmicb.2012.00218

This article was submitted to Frontiers in Fungi and Their Interactions, a specialty of Frontiers in Microbiology.

Copyright (c) 2012 Ruas, Carvalho and Roque-Barreira. This is an open-access article distributed under the terms of the Creative Commons Attribution Non Commercial License, which permits noncommercial use, distribution, and reproduction in other forums, provided the original authors and source are credited. 